\title{
STATIC AIR-GAP ECCENTRICITY FAULT DETECTION OF INDUCTION MOTOR USING ARTIFICIAL NEURAL NETWORK (ANN)
}

\author{
Khaled Mohammed Bir Gamal ${ }^{1}$, Supriya P. Panda ${ }^{2}$, M. V. Ramana Murthy ${ }^{3}$ 网 \\ ${ }^{1}$ Research Scholar, Department of Electrical \& Electronics Engineering, Manav Rachna \\ International Institute for Research and Studies, Faridabad, India \\ ${ }^{2}$ Professor, Department of Computer Science and Engineering, Manav Rachna International \\ Institute for Research and Studies, Faridabad, India \\ ${ }^{3}$ Professor(R), Department of Mathematics \& Computer Science, Osmania University, Hyderabad, \\ MGIT(P), Hyderabad, India
}

DOI: https://doi.org/10.29121/granthaalayah.v8.i8.2020.1146

Article Type: Research Article

Article Citation: Khaled

Mohammed Bir Gamal, Supriya P.

Panda, and M. V. Ramana Murthy.

(2020). STATIC AIR-GAP

ECCENTRICITY FAULT DETECTION

OF INDUCTION MOTOR USING

ARTIFICIAL NEURAL NETWORK

(ANN). International Journal of

Research -GRANTHAALAYAH, 8(8),

377-385.

https://doi.org/10.29121/granthaa

layah.v8.i8.2020.1146

Received Date: 14 August 2020

Accepted Date: 31 August 2020

Keywords:

Induction Motor

Air Gap Eccentricity Fault

Motor Current Signature Analysis

(MCSA)

Artificial Neural Network (ANN)

MATLAB Software

\begin{abstract}
Induction motor plays an important role in the industrial, commercial and residential industries, owing to its immense advantages over the opposite types of motors. Such motors have to operate under different operating conditions that cause engine degradation leading to fault occurrences. There are numerous fault detection techniques available. There are numerous fault detection techniques available. The technique used in this paper to prove the effect of static air gap eccentricity on behaving or performing of the three-phase induction motor is the artificial neural network (ANN) as ANN depends on detecting the fault on the amplitude of positive and negative harmonics of frequencies. In this paper, we used two motors to achieve real malfunctions and to get the required data and for three different load tests. In this paper, we adopted MCSA to detect the fault based on the stator current. The ANN training algorithm used in this paper is back propagation and feed forward. The inputs of ANN are the speed and the amplitudes of the positive and the negative harmonics, and the type of fault is the output. To distinguish between healthy and faulty motor, the input data of ANN are well-trained via experiments test. The methodology applied in this paper was MATLAB and present how we can distinguish between healthy and faulty motor.
\end{abstract}

\section{INTRODUCTION}

Induction machines are the basis of all modern industries. Even so, as other motors, they will finally fail due to its heavy-duty work, amid poor working, manufacturing, and composition factors. The cause of the damage may be internal or external factors; all factors are then categorized as mechanical or electrical faults depending on the rotor or stator part's source of the faults or faults depending on the position or origin of the fault as seen in Fig. 1 [5].

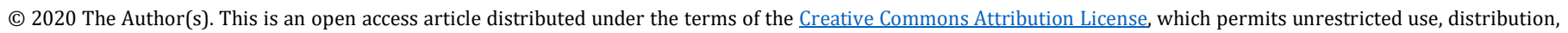
and reproduction in any medium, provided the original author and source are credited. 


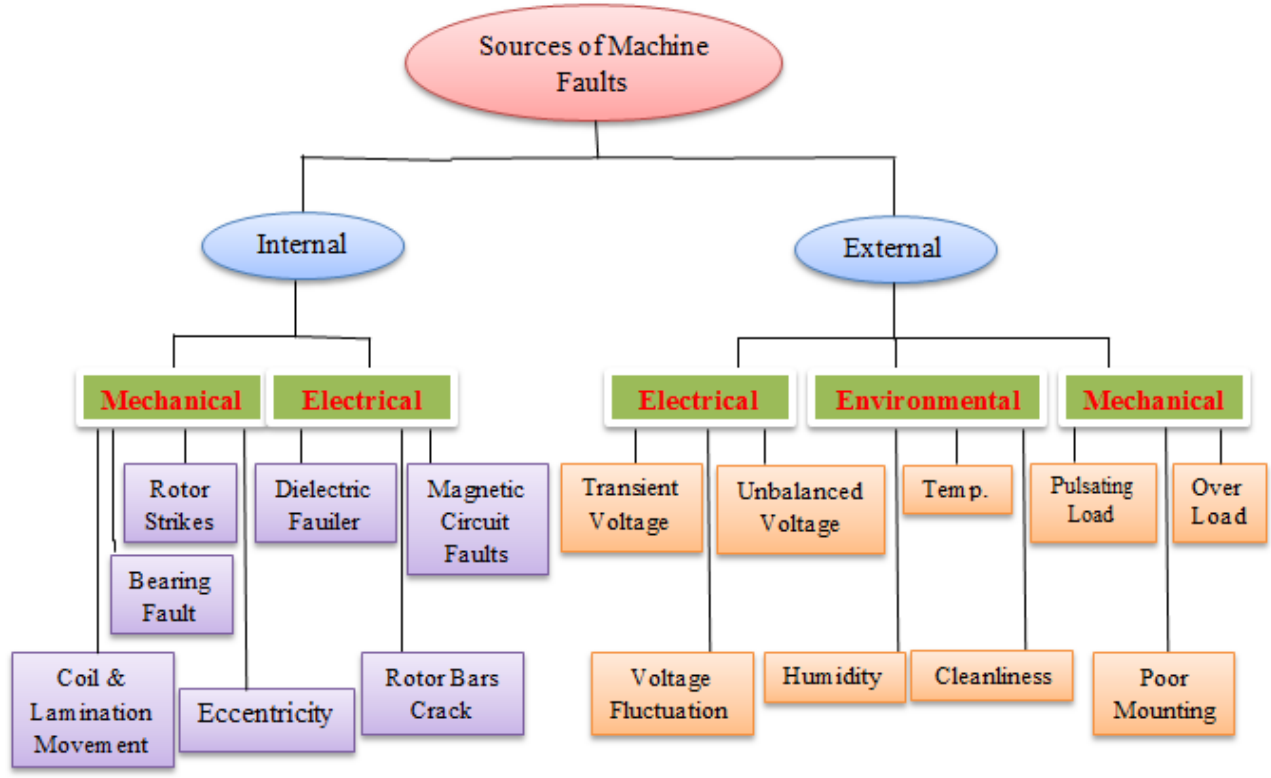

Figure 1: Sources of induction motor faults

\subsection{AIR-GAP ECCENTRICITY}

The air-gap eccentricity is a very significant problem in induction motors; it is caused by unequal air gap and calls eccentricity fault. There are two kinds of air-gap eccentricity, the dynamic air-gap eccentricity (DE), the static air gap eccentricity (SE), and combination of both types called mixed eccentricity.

In the ideal case, the geometric axis of the rotor and stator are same as in Fig. 2a, in case of static eccentricity the rotor rotates about its geometric axis as shown in Fig. $2 \mathrm{~b}$, which is not the geometric axis of the stator, in case of dynamic eccentricity as depicted in Fig. 2c; the rotor is not concentric and rotates around the stator's geometric axis [7].

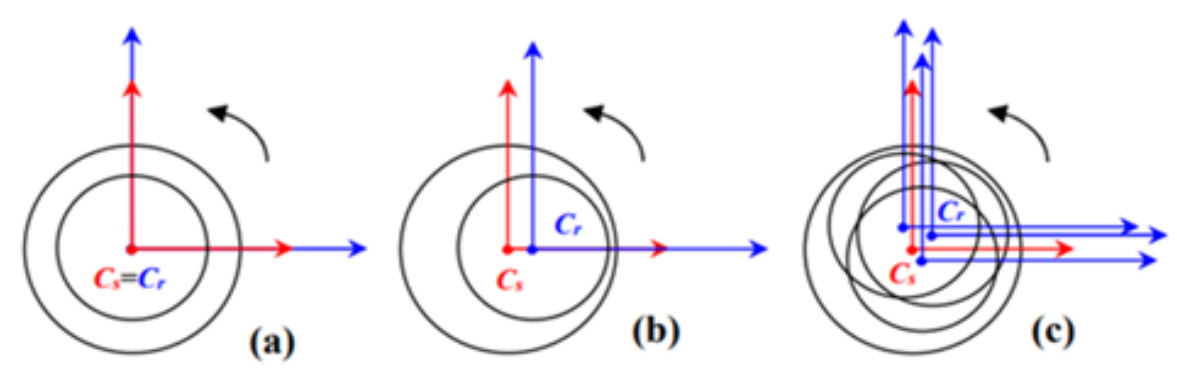

Figure 2: Types of eccentricity faults (a) concentric rotor (b) static eccentricity (c) dynamic eccentricity

The equation of the eccentricity frequency in stator current of an induction motor can be calculated as:

$\mathrm{f}_{\mathrm{ec}}=\mathrm{f}_{1}\left[\left(\mathrm{k}_{1} \mathrm{R} \pm \mathrm{n}_{\mathrm{d}}\right)(1-\mathrm{s}) / \mathrm{p} \pm \mathrm{v}\right]$

Where,

$\mathrm{f}_{\mathrm{ec}}=$ eccentricity frequency

$\mathrm{f}_{1}=$ supply frequency

$\mathrm{k}_{1}=$ any integer

$\mathrm{R}=$ number of rotor slots

$\mathrm{n}_{\mathrm{d}}=$ eccentricity order

$\mathrm{s}=\operatorname{slip}$ 
$\mathrm{p}=$ number of pair of poles

$\mathrm{v}=$ order of stator time harmonics that are present in the power supply of the motor.

\section{STATIC ECCENTRICITY}

Static eccentricity is taken place when the symmetrical axes of the rotor have the same center with the rotational axis of the rotor, but they are dislocated with the symmetrical axis of the stator; hence it fixed the radial air-gap length location. In this manner, the mutual inductance across the rotor and stator, and the self and mutual inductance between the different phases of the rotor are a rotor angular function. The mutual and self-inductance are independent of the location of the rotor angular, exactly like a healthy motor. Fig. 3 shows the static eccentricity in induction motor [9].

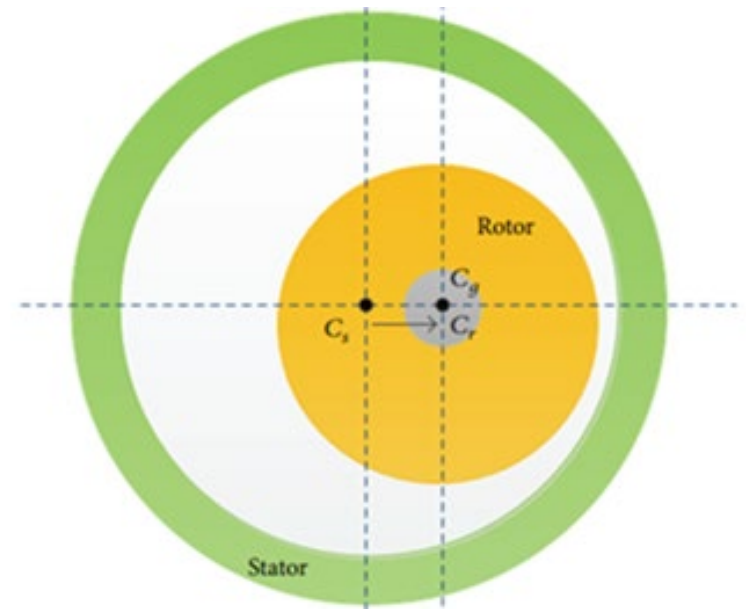

Figure 3: Cross-section of static eccentricity of $I M, C_{s}$ is the center of the stator, $C_{r}$ is the center of the rotor, $C_{g}$ is the center of rotation

The static eccentricity in the induction motor leads to an asymmetric air-gap, this asymmetric air-gap caused by the magneto-motive force of the stator by the continuity of the rotor electro-motive force harmonics. This process can be applied for the electro-motive force of the stator according to the magneto-motive force of the rotor. Therefore, the magneto-motive force and the permeance produce the flux in the air-gap that produces another filed in the air-gap; this field contains basic components, rotor and stator magneto-motive force, rotor and stator permeance, and other components due to saturation. Fig. 4 shows the air-gap field which describes the distribution of the flux density in the air-gap [5].

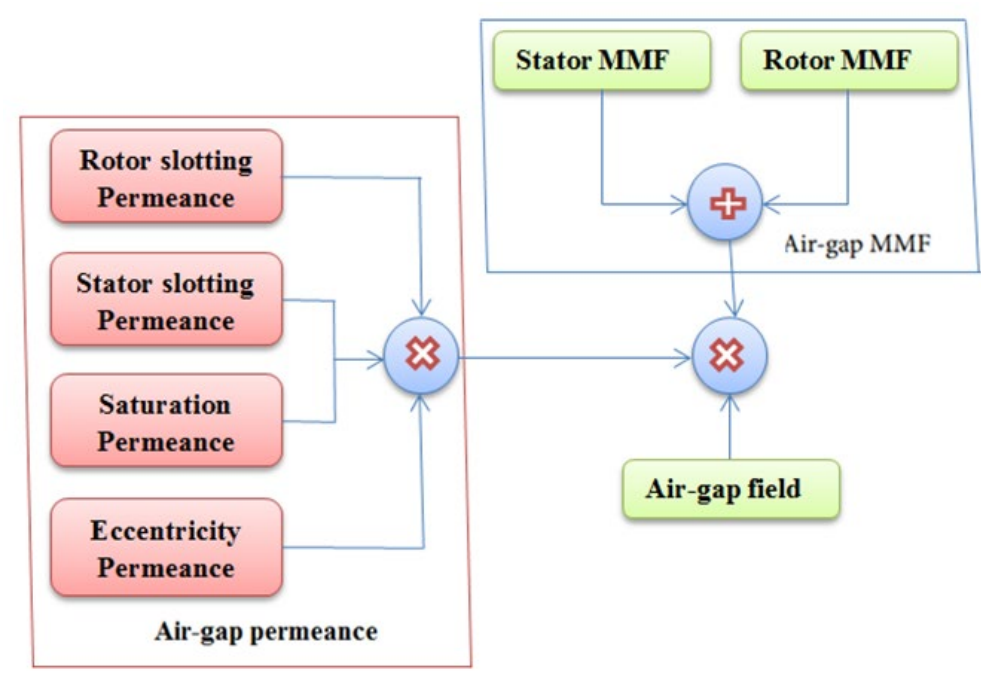

Figure 4: The computation style of air-gap field 


\section{FAULT MONITORING TECHNIQUES}

The monitoring techniques used for detecting the induction motor faults are [6]:

1) Vibration monitoring

2) Noise monitoring

3) Thermal monitoring

4) Partial discharge monitoring

5) Voltage monitoring

6) Current monitoring

\section{MOTOR CURRENT SIGNATURE ANALYSIS (MCSA)}

According to the Electric Power Research Institute, the current monitoring technique is most widely used, and it is widely used in fault detection of induction machine techniques. And depending on the institute statistics, around $40 \%$ of induction machine faults are due to the stator faults. MCSA has been used successfully in the detection of different faults such as static and dynamic eccentricity, bearing faults, stator faults as well as rotor bar faults. By using the MSCA technique, we compute the harmonic amplitude current which can be detected by this fault [6]. MCSA used to detect the eccentricity fault by monitoring the frequency component (fec $=\mathrm{kfrm}+\mathrm{f} 1)$ [8].

For analyzing the harmonic spectrum, we introduce a new signal process method which is called Fast Fourier Transform (FFT) instead of ordinary frequency in stator current and induction motor fault diagnose.

The way of identifying the faults in induction machines include two basic processes, creation process in which the signal is identified, and then identification process in which the data is divided and sampled and then normalize and filter. Then the data converted to harmonics via the First Fourier Transform algorithm [2].

\section{ARTIFICIAL NEURAL NETWORK}

The Artificial Neural Network (ANN) is like a human brain. This is because we use the forces associated with neurons, called tangential weights, to acquire knowledge, to learn and maintain knowledge. There is a similarity between ANN and neurology, which allows biologists to rely on the evolution of biological phenomena.

The architecture of ANN represents a group of artificial neuron linked together to form a network which have neurologic characteristic such as storing practical and experimental information to make them useable by adapting the weights, as it is describe in Fig. 5. The main component of this network structure is the relationship with the artificial neuron. Each artificial neuron is an object of the process that can process and store information. Each link can increase, decreases or block the transfer of information throughout it. ANN consists of input, summation and activation and output connection function [10].

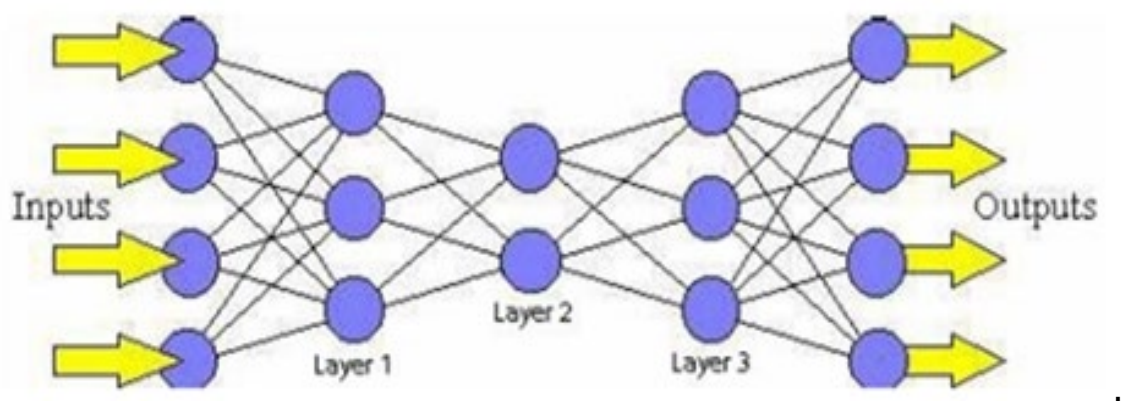

Figure 5: Structure of a neural network

The most difficult and important matter while designing an appropriate ANN is how to choose the proper number of hidden layers and its number of neurons. This layer represents the inner data and how the information is transferred from input to output layers. If there are few or many neurons in this layer, it will effect on the operation of the network. If high number of neurons are present, over trained is occur. So an ideal design is required for the number of neurons in the hidden layer [1]. 
Fig. 6 displays the logical structure for the ANN-based system of detection of faults in induction motor [4].

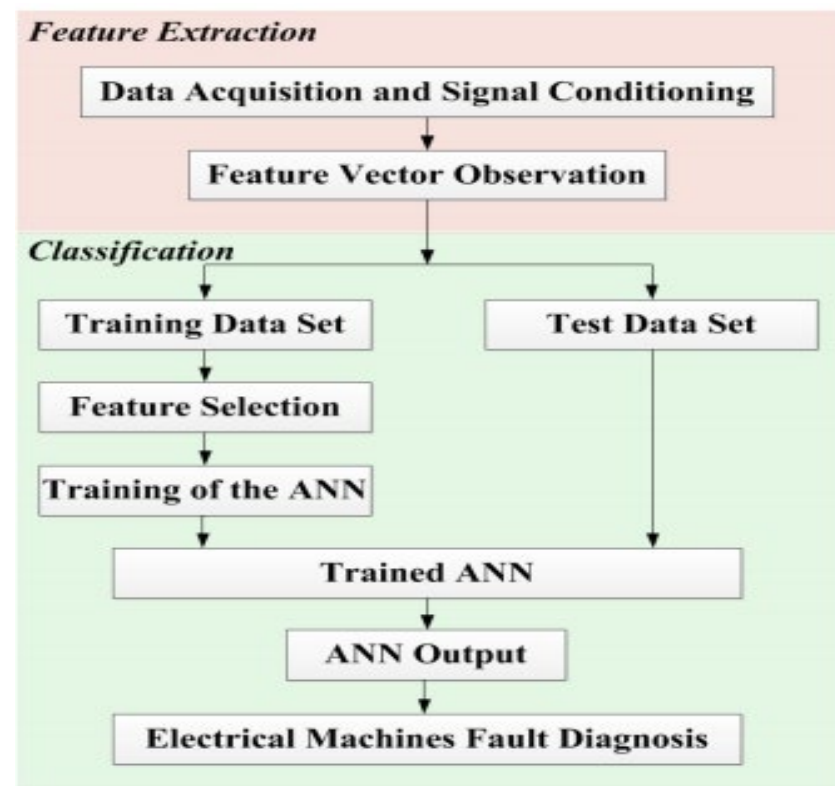

Figure 6: the logical structure of the ANN based fault detection method

The study contains three tests on healthy, faulty and the eccentricity fault motor at different loads.

\section{TEST FOR HEALTHY MOTOR}

The FFT Algorithm is applied on the waveform of stator current for different loads of healthy induction motor:

\subsection{TEST AT NO-LOAD}

The parameters used for testing the healthy induction motor at no-load, are slip, speed and current, where: slip= 0.0165 , speed $=2960 \mathrm{rpm}$ and line current $=3.6 \mathrm{~A}$. Fig. 7 shows both the waveform of the current and its corresponding FFT.

a )

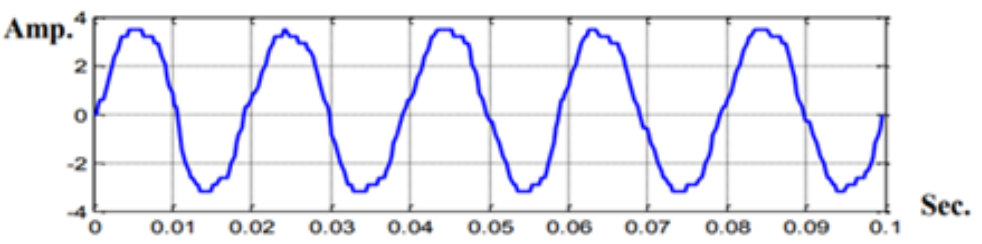

b)

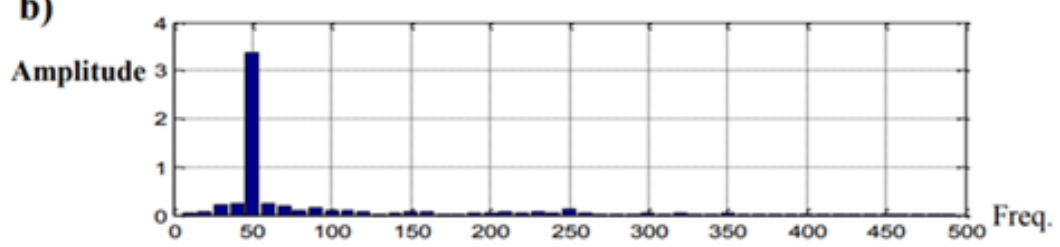

Figure 7: current waveform in healthy motor at no-load (a) Line current waveform (b) Corresponding FFT

\subsection{TEST AT HALF -LOAD}

Same paramour used for this test, the values of slip=0.034, speed $=2910 \mathrm{rpm}$ and line current= 5.1A. Fig. 8 shows the waveform and FFT of the signal at half load. 
a)

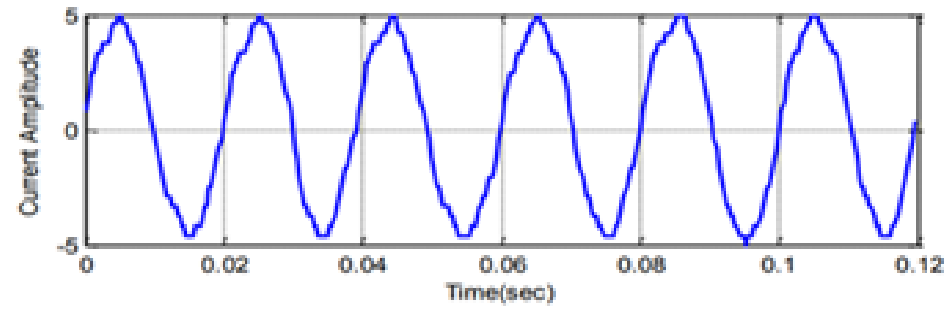

b)

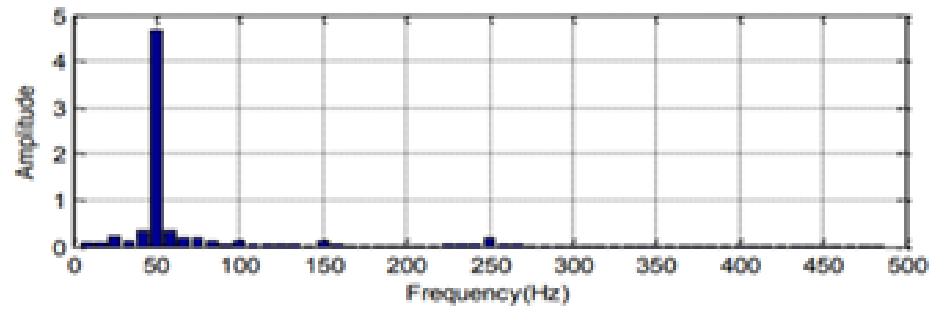

Figure 8: current waveform in healthy motor at half-load (a) Line current waveform (b) Corresponding FFT

\subsection{TEST AT FULL -LOAD}

In this test the value of the three parameters are: slip $=0.051$, speed $=2860 \mathrm{rpm}$ and line current $=8.55 \mathrm{~A}$. Fig. 9 shows the wave form of the current and it's FFT at full-load.

a)

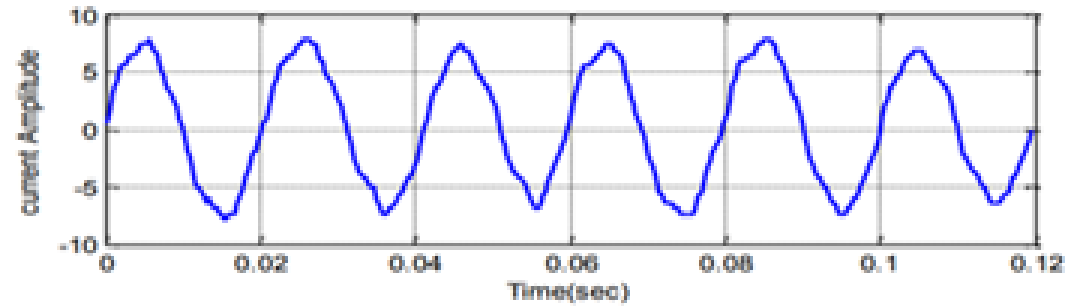

b)

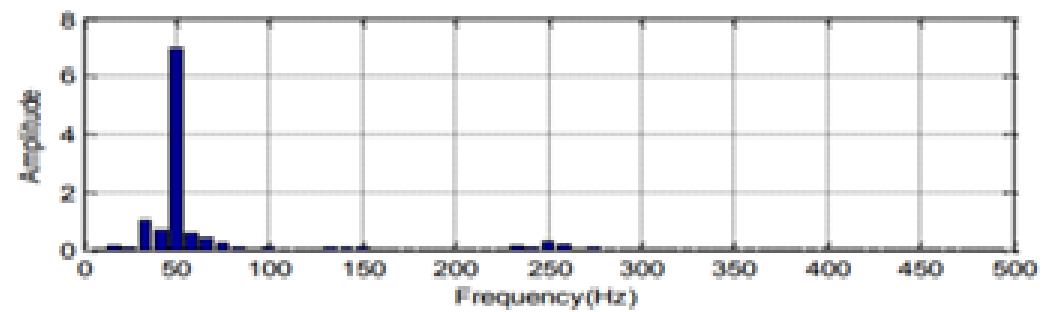

Figure 9: current waveform in healthy motor at full-load (a) Line current waveform (b) Corresponding FFT

\section{TEST AT ECCENTRICITY FAULT}

After testing the healthy motor, motor at static eccentricity fault is tested.

The harmonic analysis of the line current were determined by the data acquired from (No-load, Half-load and Full-load) tests. By using equation (1), we can calculate the side band frequency for the three cases mentioned above, where $\mathrm{R}=20$ and $\mathrm{n}_{\mathrm{d}}=0$ for all cases.

\subsection{TEST AT NO-LOAD}

First step, describe the process at No-load, where; slip=0.062, current $=3.55 \mathrm{~A}$ and speed $=2815 \mathrm{rpm}$. Fig. 10 shows the waveform of line current and FFT waveform. 
a)

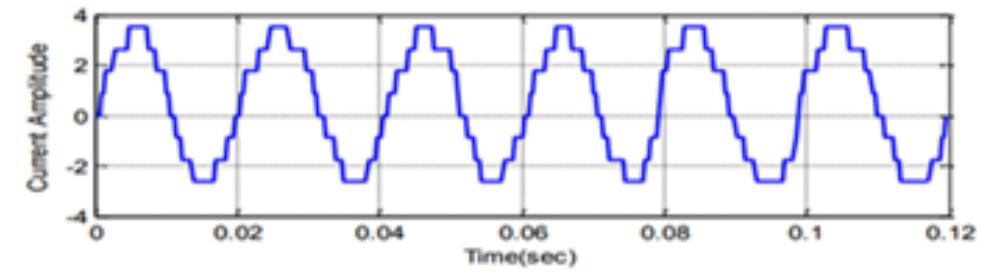

b)

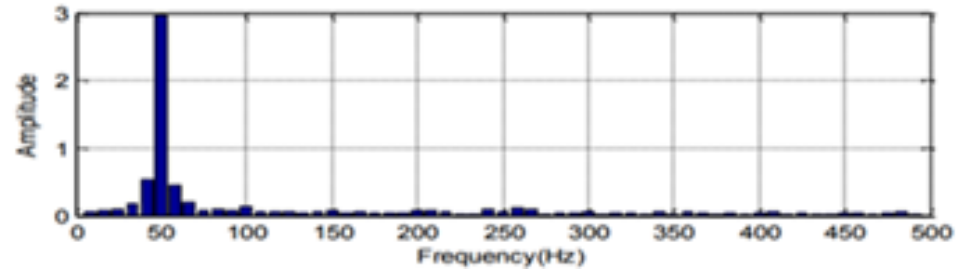

Figure 10: current waveform from waveform of eccentricity fault at no-load (a) Line current (b) FFT

\subsection{TEST AT HALF-LOAD}

Second test, present the process at Half-load, where; slip=0.008, current=5.1A and speed $=2800 \mathrm{rpm}$. Fig. 11 , shows the waveform of line current and FFT waveform.

a)

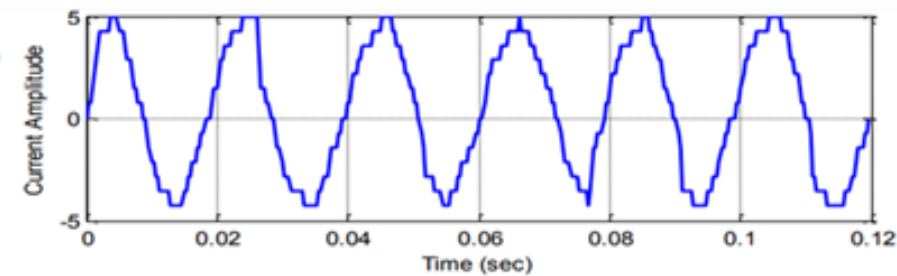

b)

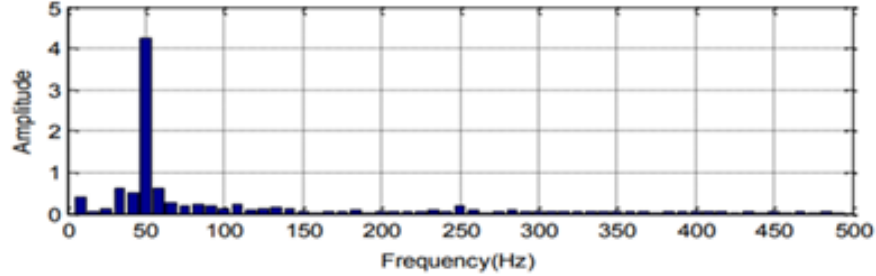

Figure 11: current waveform stator eccentricity fault at half-load (a) Line current waveform (b) FFT

\subsection{TEST AT FULL-LOAD}

Third test, describe the process at Full-load, where; sleep=0.094, current $=8.6 \mathrm{~A}$ and speed $=2725 \mathrm{rpm}$. Fig. 12 , shows the waveform of line current and FFT waveform.

a)

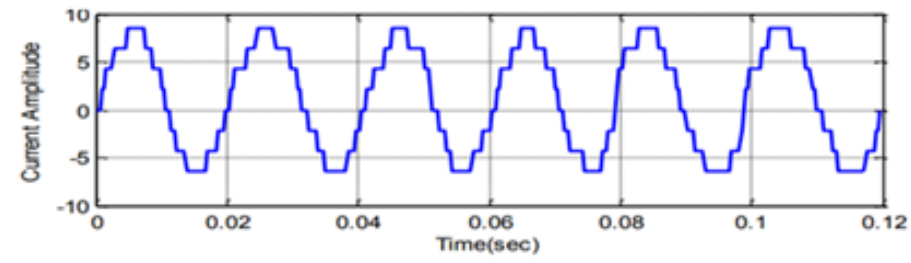

b)

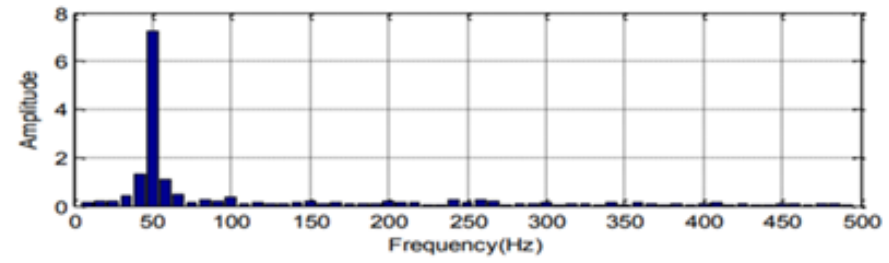

Figure 12: current waveform stator eccentricity fault at full-load (a) Line current waveform (b) FFT International Journal of Research -GRANTHAALAYAH 


\section{IDENTIFYING THE FAULTSBY TRAINING OF ANN}

Two induction motors, one healthy motor and other faulty motor $2.2 \mathrm{~kW}$ rating, have been used to obtain the real fault and data needed at the three types of load. We get the two signals current and speed from these two motors. We used Matlab software for writing the program containing FFT algorithm and the amplitude of harmonic frequency. To improve performance of ANN, the input data must be correctly chosen before inserting them to the network. There are two outputs, one indicates the motor is faulty and the other indicates that the motor is healthy. We select two neurons for the hidden layer for the training process.

Then the Network will train depending on the side bands amplitude, 25 data set for the static eccentricity fault out of 125 data set are used for training the network. To achieve the required goal, the supervised training needs guideness. In this paper a FFT are used and trained using active function of tan sigmoid type, with back propagation algorithm. The inputs and outputs of the ANN are shown in fig. 13.

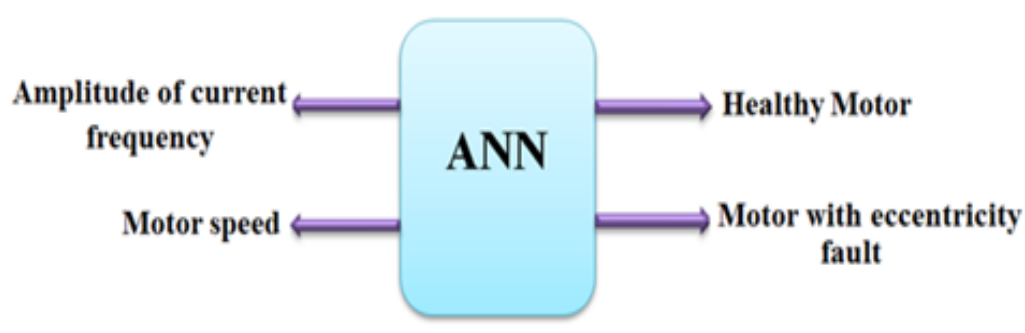

Figure 13: Inputs and outputs of ANN

\section{AFTER TRAINING THE NETWORK}

After training the network successfully, it'll then use the network to detect the static eccentricity fault. This training portrayed the sum of squared error concerned with number of iterations in fig. 14, the training parameter goal set for the program was an error (1e-25), but the training outcome was less than the program error as shown in Fig. 14.

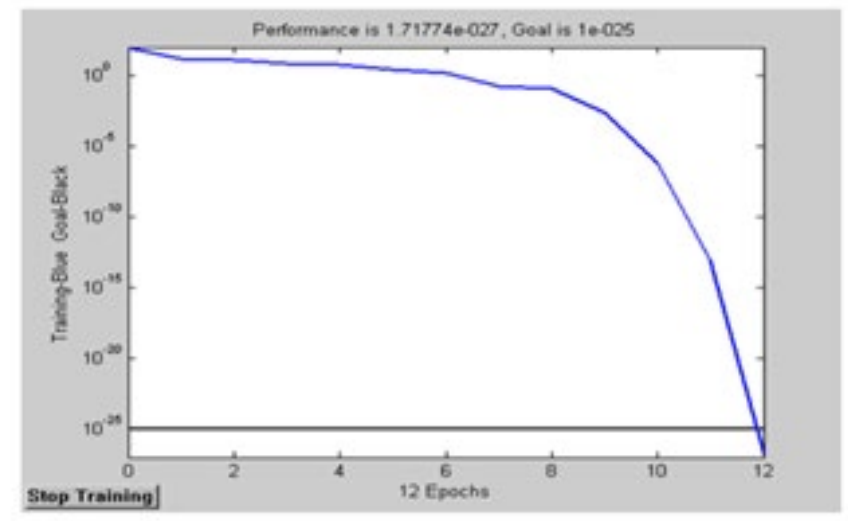

Figure 14: The performance of ANN training

\section{CONCLUSION AND FUTURE WORK}

MCSA used to measure the static eccentricity in the engine by close analysis of an induction motor. MCSA is a v ery accurate and easy way to diagnose the fault, as it needs only one stator present. The test method suggested a mi $\mathrm{x}$ of high-performance ANN and MCSA techniques.

The diagnosis system proposed a combination of MCSA technique and high-performance ANN. By this relationship between MCSA and ANN, the efficiency of detecting the static eccentricity fault increases.

In this paper, the technique used for data extraction is FFT, which extracts accurate information from the signal of stator current. 
The experimental results show that the ANN with feedforward and learning rule of backpropagation type and Tanh Axon transfer function with two elements in the hidden layer is a very suitable network for detecting faults in an induction motor with an accuracy of $100 \%$.

However, one of ANN's key drawbacks is that it only responds to the discovery of the fault on which it was trained, and in the event of a new fault, ANN can't detect that fault because, the new fault has not been learned and thus the use of ANN is futile.

For this reason, Fuzzy Logic technique is most useful in this case.

\section{SOURCES OF FUNDING}

This research received no specific grant from any funding agency in the public, commercial, or not-for-profit sectors.

\section{CONFLICT OF INTEREST}

The author have declared that no competing interests exist.

\section{ACKNOWLEDGMENT}

None.

\section{REFERENCES}

[1] Amini J. 2008, "Optimum learning rate in back-propagation neural network for classification of satellite images (IRS-1D)," ScientiaIranica, vol. 15, no. 6, pp. 558-567, 2008.

[2] Anant G. Kulkarni, Dr. Manoj Jha, Dr. M. F. Qureshi 2014, "Simulation of Fault Diagnosis of Induction Motor Based on Spectral Analysis of Stator Current Signal Using Fast Fourier Transform”, IJISET - International Journal of Innovative Science, Engineering \& Technology, Vol. 1 Issue 4, June 2014, ISSN 2348 - 7968.

[3] Anjali Jawadekar, SudhirParaskar, SaurabhJadhav et al.2014," Artificial neural network-based induction motor fault classifier using continuous wavelet transform", Systems Science \& Control Engineering: An Open Access Journal, ISSN: (Print) 2164-2583 (Online) Journal homepage, 2:1, 684-690, DOI: 10.1080/21642583.2014.956266.

[4] Ciprian Harlişca, Ilhem Bouchareb, Lucia Frosini et al. 2013," Induction Machine Bearing Faults Detection Based on Artificial Neural Network", CINTI 2013 -14th IEEE International Symposium on Computational Intelligence and Informatics ,19-21 November 2013, Budapest, Hungary.

[5] Guldemir H. 2003, "Detection of air gap eccentricity using line current spectrum of induction motors", Electric Power Systems Research, vol. 64, no. 2, pp. 109-117, 2003.

[6] GulhaneSnehal O. and, Salodkar M. R. 2016," Review of Detection of Faults in Induction Motor", International Research Journal of Engineering and Technology (IRJET), Volume: 03 Issue: 08, Aug -2016.

[7] Halem N., Zouzou S. E., Srairi K. et al. 2015, "Detection of Static eccentricity Fault in Saturated Induction Motors by Air-gap Magnetic Flux Signature Analysis Using Finite Element Method”, Journal of Fundamental and Applied Sciences ISSN 1112-9867, 2015.

[8] Hamdani S., Touhami O., Ibtiouen R., and Fadel M. 2011," Neural Network technique for induction motor rotor faults classification -Dynamic eccentricity and broken bar faults", Conference Paper · September 2011 DOI.

[9] Mahdi Karami, NormanMariun, Mohammad RezazadehMehrjou et al. 2014," Static Eccentricity Fault Recognition in Three-Phase Line Start Permanent Magnet Synchronous Motor Using Finite Element Method", Research Article, Hindawi Publishing Corporation Mathematical Problems in Engineering, Volume 2014, Article ID 132647.

[10] Zhang Qing James ,2002 “Artificial Neural Network - Advanced Theories \& Industrial Application “, Research study for the degree of doctoral of philosophy in Environmental Engineering, Department of Civil \& Environmental Engineering, University of Alberta. 